\title{
The Limits of Labelling: Incidental Sex Work Among Gay, Bisexual, and Queer Young Men on Social Media
}

\author{
Max Morris $^{1}$ (i) \\ Accepted: 6 June 2021 / Published online: 19 June 2021 \\ (c) The Author(s) 2021
}

\begin{abstract}
Introduction The term incidental sex work refers to forms of casual, occasional, unsolicited commercial sex, arranged between gay, bisexual, and queer men on social media platforms such as Grindr. This paper explores the limits of labelling sexual identities, and how definitions of "sex" and "work" have become increasingly unstable in the digital age.

Methods This study used mixed methods, with the primary mode of data collection being qualitative interviews with young gay, bisexual, and queer men conducted between May 2015 and April 2016. The interviews incorporated a nine-point sexuality scale and photo-elicitation procedures to prompt further discussions. Through the participant recruitment process, the study also generated an informal survey of 1473 Grindr users aged 18 to 28 , finding that $14.6 \%$ had been paid for sex, most of whom $(8.2 \%)$ had done so "incidentally."

Results The 50 interview participants discussed being paid for sex 358 times. This paper focuses on their narratives of labelling, identity politics, sexual normativity, and social stigma. All participants distanced themselves from labels such as "prostitute," "rent boy," or "sex worker" given that their behaviours were not seen as "regular" or "professional" enough, alongside seeking to avoid association with stigmatising stereotypes of sex work. These results are compared with the participants' experiences of coming out as gay, bisexual, and queer.

Discussion These narratives are interpreted using queer theory to understand those whose behaviours and identities do not conform to normative (legal, medical, social) discourses of sex work. The implications of this hidden population for campaigners, policymakers, and healthcare practitioners are discussed, contributing to ongoing debates around harm reduction and social policy.
\end{abstract}

Keywords Labelling $\cdot$ Post-identity $\cdot$ Queer theory $\cdot$ Sex work $\cdot$ Social media

\section{Introduction}

This paper looks at the attitudes and experiences of young gay, bisexual, and queer men who agreed to sell sex occasionally on social media platforms but did not advertise or label themselves as sex workers. To describe this phenomenon, I have used the term incidental sex work "as a descriptive term (encompassing a wide range of commercial sexual behaviours, both direct and indirect), rather than a form of labelling" (Morris, 2018, p. 224). Focusing on the fifty interview participants' narratives around sexual labels, politics, and norms, I draw on queer theory to destabilise the

Max Morris

M.J.Morris@Kingston.ac.uk

1 Department of Criminology and Sociology, Kingston University London, Kingston-Upon-Thames, UK boundedness of "sex worker" as an identity category. The paper begins by exploring the modern tendency to categorise sexual behaviours as stable identities. It concludes by discussing the implications of this study for both health policy and global campaigns to decriminalise sex work.

\section{Constructions of Sexual Identity}

In Volume 1 of The History of Sexuality Foucault (1978) described how the homosexual had been discursively constructed as a "type of life," "singular nature," or "species" by law, medicine, and sexology in the nineteenth century; this contrasted with pre-modern conceptualisations of sodomy as a "category of forbidden acts," "habitual sin," or "temporary aberration" (p. 43). Importantly, Foucault challenged the repressive hypothesis-often associated 
with prudish moral attitudes towards sex, for example in Victorian England (c.f. Lister, 2020)—by showing how the ways in which bodies have been categorised and thus understood could be useful for seemingly contradictory political projects:

There is no question that the appearance in nineteenthcentury psychiatry, jurisprudence, and literature of a whole series of discourses on the species and subspecies of homosexuality, inversion, pederasty, and "psychic hermaphrodism" made possible a strong advance of social controls into this area of "perversity"; but it also made possible the formation of a "reverse" discourse: homosexuality began to speak in its own behalf, to demand that its legitimacy or "naturality" be acknowledged, often in the same vocabulary, using the same categories by which it was medically disqualified. (Foucault, 1978, p. 101)

Sexualities scholarship has drawn on this observation to critique the essentialising tendency of not only traditional research methods, but also contemporary rights-based campaigns for sexual minorities, including the now-familiar "born this way" narrative (Adler, 2018; Walby, 2012; Weeks, 2017).

Historians of sex work have also noted how women were increasingly categorised, criminalised, moralised, and pathologised during this period through constructions of the prostitute, or so-called "fallen woman" (Chateauvert, 2014; Walkowitz, 1982). Grant (2014) has noted the changing nature of language, contrasting pre-modern conceptions of sexual behaviour with modern conceptions of sexual identity, where the term "prostitute" had been used as a verb (to prostitute) rather than a noun (the prostitute). Relatedly, Augustín (2007) has described a similar etymological shift occurring around the term "whore" in this period:

"Whoring" referred to sexual relations out of marriage and connoted immorality or promiscuity without the involvement of money, and the word whore was used to brand any woman who stepped outside current boundaries of respectability. The emphasis was on the behaviour, not the personal identity. (p. 101)

For example, in his Lectures on Female Prostitution, Wardlaw (1842) held that the repetition of sex "for hire" generated "designations of character," which could not be applied to "a solitary act" (p. 14). Male sex work researchers have also described how "prostitutes came to the particular attention of the early sexologists because many of them seemed to lie on a border between 'normal' sexuality and the new idea of 'homosexuality' that they were formulating" (Kaye, 2014, p. 39). Therefore, the central themes of this paper sit within a body of research literature about the discursive construction of sexual identity which is theoretically and empirically informed (see Plummer, 1995; Walkowitz, 1982; Weeks, 2017).

One theorist who took a historical view of the discursive construction of sexual morality was Rubin (1984), whose essay "Thinking sex: Notes for a radical theory of the politics of sexuality" made the case for a more "anthropological" (relativist) approach to understanding sexual diversity. Her model of the "charmed circle" and "outer limits" of sexual respectability has informed many areas of sexualities research (see Shrage, 1994; Tyler, 2014; Vance, 2011), and intersecting hierarchies relevant to this paper:

According to this system, sexuality that is "good," "normal" and "natural" should ideally be heterosexual, marital, monogamous, reproductive, and non-commercial... Any sex that violates these rules is "bad," "abnormal," or "unnatural." Bad sex may be homosexual, unmarried, promiscuous, non-procreative, or commercial. (Rubin, 1984, pp. 280-1)

Rubin's work was profoundly influenced by Foucault, noting his argument that "desires are not preexisting biological entities, but rather, that they are constituted in the course of historically specific social practices" (p. 276). Therefore, when considering incidental sex work among gay, bisexual, and queer men, it is important to keep these intersecting forms of sexual privilege and prohibition in mind, as they operate at the cultural level. Although this paper does not engage directly with labelling theory, given its focus on the limits of labelling, it is also worth noting Plummer's (1979) argument that such perspectives may also contribute to practical projects such as "decriminalisation, deinstitutionalisation, demedicalisation, deprofessionalisation and the creation of movements concerned with such activities" (p. 223).

Finally, this paper is theorised by drawing on Foucault's (1977) conceptualisation of modern disciplinary mechanisms which operate at the discursive level such as normalising judgement (p. 177). This refers to the processes of coercion, classification, and criminalisation which emerged in systems of standardisation based on principles of "formal equality" (from education to healthcare), where "the norm introduces, as a useful imperative and as a result of measurement, all the shading of individual differences" (p. 184). Such differentiations and measurements are made possible through the imposition of labels which designate class, rank, qualify, and so forth. The maintenance of social hierarchy through the utilitarian logics of measurement and surveillance were articulated first in Discipline and Punish, where Foucault (1977) famously argued: "Visibility is a trap" (p. 200). Relating this to the central themes of this paper-the limits of labelling and sexual identity politics-the next section explores how queer theorists have drawn on these ideas to critique normative, rights-based campaigns for "equality" more recently (see Adler, 2018). 


\section{Queering Legal Norms and Labels}

In the latter half of the twentieth century, new labels have emerged to characterise "homosexuality" and "prostitution" which have-depending on one's perspectivebeen defined as either affirmative or assimilationist. For example, following the decriminalisation of homosexuality in England and Wales in 1967 and the Stonewall riots of 1969, "gay liberation" movements have achieved greater visibility globally (Morris, 2019). There has, however, been a consistent tension between the "radical" and "respectable" elements of the movement for lesbian, gay, bisexual, and trans (LGBT) rights and recognition, which drew on strategies of the preceding civil rights and women's rights movements. Drawing on Foucault's problematisation of "formal equality," Adler (2018) has used the term "LGBT equal rights discourse" to describe an approach to rights-based advocacy work and law reform (e.g. marriage equality and military participation) which has tended to characterise gender and sexual minorities according to a set of "recognizable tropes that tell us about our virtues, our vulnerabilities, and our relationships" (p. 3). Scholars have also critiqued the growing tendency of LGBT organisations to endorse carceral interventions such as hate crime legislation, where the citizenship of a formerly criminalised community is premised on a state's willingness to criminalise others, on our behalf, in this case premised on the state's "protection" of certain characteristics or identities (Lamble, 2013; Spade, 2015).

To draw another parallel, the term "sex worker" was introduced in the late 1970s by Leigh (1997) who, after attending a feminist conference in San Francisco, suggested that the event's title, "Sex Use Industry," should be changed to "Sex Work Industry," seeking to emphasise her "role as actor and agent in the transaction" (p. 230). Here, Foucault's point about the potential for disqualifying language to make possible the formation of a reverse discourse is apparent. The term "sex work" became more widely adopted throughout the 1980s and 1990s and is now adopted by global health and human rights organisations including Amnesty International, UNAIDS, and the WHO (see discussion). Relatedly, the discursive construction of "vulnerability" has been used both as a justification for (de)criminalisation, such as the "Nordic model," and greater state intervention through hate crime legislation, such as the "Merseyside model" (Campbell, 2014). Sex work researchers have also noted an increased emphasis on "welfarism" within policy, placing emphasis on harm reduction, health, and safety issues, rather than criminalisation (O’Neill, 2001; Sagar \& Jones, 2017).

Part of this shifting use of language has been captured by terms such as "queer" becoming increasingly popular in both academic and activist circles. Masiero (2017) has highlighted three ways in which the term has been used-as a noun ("a post identity-identity"), as a verb ("to queer"), and as a concept ("queer theory")—united by "a constant interrogative stance towards what is taken for granted as being normal" (p. 132). For example, Whittle (2005) has suggested that queer theory can be defined by "the deconstruction and the refusal of labels of personal sexual activity, and it is also concerned with the removal of pathologies of sexuality" (p. 117). Queer theory is often distanced from "gay and lesbian studies," which depended on the construction and continuity of such identity labels (see Brown, 1997, for a comparative critique of "women's studies"), and is critical of the conservative tendencies toward essentialism or identarianism about gender and sexuality (Epstein, 1994; Rubin, 1984; Vance, 2011). The destabilisation of identity labels constructed by medicine and law, alongside "mainstream" cultural representation, is therefore central to queer theory. As Edelman (2004) has argued: "Queerness can never define an identity: it can only disturb one" (p. 17).

As with LGBT equal rights discourse (Adler, 2018), tensions have emerged around issues of representation and normativity for sex workers, in efforts to prioritise formal legal equality (e.g. the right to unionise and have safe working conditions). For example, Weitzer (2017) has argued that individual sex workers should emphasise agency, deny harms, and define their work "as a service profession like any other," further noting that "the gay rights movement shows that the repeal of discriminatory laws is vitally important but hardly sufficient for normalisation" (pp. 720-2). Responding to this, Chapkis (2017) cautioned that:

Despite [Weitzer's] suggestion that effective strategies to end sex work stigma should be based on the tactics of "deviance liberation movements", his focus is entirely on "normalization" not "liberation." For example, as a form of resistance to stigma, he notes that individual sex workers might tell stories about prostitution involving "full agency" to distinguish their work from "disreputable forms of sex work (e.g. street prostitution)". "Derogatory words" like "whore" could be replaced by more neutral terms... But any categorization of some sex workers as "disreputable" - and other workers, in a patriarchal, racist, capitalist, carceral state, as having "full agency" - reinforces the problem of stigma rather than resolves it. (p. 744)

Relatedly, Grant (2014) has suggested that the gay liberation movement's focus on respectability politics was comparable with sex worker "normalisation," which cannot resolve these problems: "The effect of such strategies would be, at best, to shift stigma, not to eliminate it" (p. 743). Shrage (1994) further argued that if the focus of research in this 
area is "exclusively on socially marginal sexualities, then we will contribute to the further marginalisation of sexual minorities" (p. 81).

Rather than engaging directly with these academic disputes, this paper poses an epistemological and empirical problem for the categorisation of sex work per se, by sharing the narratives of gay, bisexual, and queer men for whom such labels or interventions have little or no relevance, especially in terms of formal legal equality (Adler, 2018). For example, Walby (2012) has drawn on queer theory to critique sex worker identity politics for its tendency to focus narrowly on issues of decriminalisation, despite being viewed as irrelevant by the online male escorts he interviewed. Relatively few studies have attempted to combine queer theory with empirical data to explore such tensions. Nonetheless, the themes of identity politics, sexual normativity, and social stigma have been a focus of male sex work research generally, including in this paper, something which I will return to in the discussion section.

\section{Sex Work on Social Media}

Perhaps the most significant shift in sex work research in the twenty-first century-alongside greater recognition of men who sell sex (Minichiello \& Scott, 2014) and nonbinary and trans people who sell sex (Nuttbrock, 2018)_ has been the role of internet technologies in transforming the industry (Jones, 2020; Logan, 2017; Sanders et al., 2017; Walby, 2012). For example, Jones (2015) has characterised the emerging body of empirical research about online sex work as offering "a new autonomous platform for marketing and selling sexual services that reduce risk" (p. 558), while Sanders et al. (2017) have identified some of the new risks such technologies can represent (even while improving safety generally), including doxing, outing, and harassment. Nonetheless, the internet has become an area of increased focus for policy interventions, something which this study further contributes to and comments on. In the research literature on men who sell sex, scholars have noted that online interactions between clients and sex workers may also contribute to the "convenience, safety, and satisfaction" of buying and selling sexual services (Grov \& Smith, 2014, p. 251). In Male Sex Work and Society, Minichiello and Scott (2014) argued that "new telecommunications technologies have done much to increase awareness of the diverse and dynamic nature of male sex work" (p. xiv). For example, both Mowlabocus (2010) and Tyler (2014) have examined men's use of the social networking site Gaydar to sell sex, noting how the distinctions between casual and commercial sex may be increasingly unstable on such platforms.
An argument which this paper will develop, building on the precious section, is the notion that "queer" and other (de) constructivist perspectives on sexual identity have been complimented by the material, technological changes of recent decades. One example of this can be seen in the expansion of amateur pornography and webcamming, as digital spaces in which non-normative desires can be explored (Florêncio, 2021; Jones, 2020). Indeed, as Weeks (2017) has noted:

mediated anonymously through millions of network connections, bodily intimacy is in danger of being displaced altogether, and the distinctions between men and women, heterosexual and homosexual, adults and children, the beautiful, the ugly and the damned, may dissolve easily in the millions of possible interactions in cyberspace. (p. 21)

Such technologies have expanded the possibilities for LGBT people to connect with each other, while the anonymity of social media platforms can also provide spaces for people to explore or play with desires and identities; to "come out" and contribute to the growing visibility of sexual diversity, or even meet in the "real world" (Döring, 2009; Gray, 2009). Concurrently, in recent years, researchers have noted the increasing diversity and fluidity of sexual identity labels used, especially by younger people (Diamond, 2008; Ghaziani, 2014; Morris, 2017; Savin-Williams, 2005). Terms such as "post-gay" and "post-identity" have been used to characterise this turn away from traditional identity politics.

Over the past 15 years, there have been a growing number of location-based smartphone applications available for gay, bisexual, and queer men to communicate, organise dates and sex, including Grindr, Hornet, Jack'd, Recon, and Scruff. Alongside sites such as Fitlads, LadsLads, and Squirt, these social media platforms have expanded the range of spaces in which sex (including sex work) can be arranged and negotiated, contributing to the existing literature on social networking sites (Ashford, 2009; Bonner-Thompson, 2017; Mowlabocus, 2010). Although it is likely that incidental sex work occurred before the invention of the internet (e.g. casual encounters and informal propositions made in bars and other "real-world" settings), these technologies have expanded the possibilities for such offers to be made. Drawing on an original empirical study of incidental sex work, this paper's methods and theory are thus shaped by the social media platforms on which young men have sex, and their rejection of identity labels is viewed through this lens.

\section{Methods}

This study adopted a mixed method approach which combined qualitative, quantitative, and visual elements. This aligned with "pluralistic approaches to qualitative 
research" which have borrowed from a diverse range of conceptual traditions including discourse analysis, interpretative phenomenological analysis, and narrative analysis (Frost et al., 2010, p. 442). Furthermore, Todd et al. (2004) have advocated for combining qualitative and quantitative methods as a more effective way to communicate data to diverse audiences, triangulate results and improve theory. Although the primary source of data was drawn from 50 semi-structured interviews, which included photoelicitation procedures, through the participant recruitment process, I was able to gather an informal survey of 1473 Grindr users who were 18 to 28 years old at the time of data collection (see below), alongside archival methods to explore the history of sexuality criminalisation (see above). Given this combination of approaches to gathering evidence about a hidden population, this study aligns with Halberstam's (1998) definition of queer methodology as "a scavenger methodology that uses different methods to collect and produce information on subjects who have been deliberately or accidentally excluded from traditional studies of human behavior" (p. 13). The research questions which informed this study were as follows: (1) What are the experiences of young men who sell sex incidentally using social networking sites and smartphone apps? (2) How does incidental sex work differ from other forms of sex work described in the existing literature? (3) What implications do these narratives have for sex work policy and theory?

\section{Recruitment}

Most participants were recruited through Grindr, "a geolocation-based phone dating app allowing gay men to connect with others in their proximity" (Conner, 2019, p. 1), by travelling to major cities across England and Wales (Cardiff, Bristol, Newcastle, Southampton, Birmingham, Liverpool, Manchester, and London). With the username "Research" and a photo of myself sitting in a café, the Grindr profile provided a brief description of the study (see Bonner-Thompson, 2017, who used a similar approach). Using this profile, I sent 3000 identical messages to nearby users: "Hey. Have you ever been offered money for sex online, and said yes? I'm a social researcher looking for people to interview (anonymously) about their experiences. Would you be interested in taking part?" Walby (2010) has described issues of being (mis)perceived by participants when seeking "to portray an identity as a professional sociologist conducting a rigorous study concerning male-for-male internet escorting" (p. 652), and I have elaborated on issues of reflexivity, sensitivity, and the range of methods used-which have been summarised in this section-in more detail elsewhere (see Morris, 2018).
With a $41.9 \%$ response rate, this recruitment strategy generated an incidental survey of incidental sex work practices within a sample of 1473 young urban men who used Grindr. Among those who responded to the initial recruitment question, $14.6 \%(N=215)$ had been paid for sex: $2.3 \%(n=34)$ had done so "professionally" and $8.2 \%(n=121)$ had done so "incidentally," while $4.1 \%(n=60)$ did not respond to any follow-up questions. As will be discussed below, the distinctions between "incidental" and "professional" sex work implied here can be further complicated. For example, I counted those who had performed "on set" pornography in the former category, but those who had performed webcamming "at home" in the latter. However, as Jones (2020) has noted, the emergence of "online porn tube sites has created a space for amateur pornographers to post videos of themselves... and in today's visual sexual markets there is higher value placed on pornographic imagery perceived as authentic" (p. 47). Therefore, the distinction between "professional" and "amateur" has also become increasingly destabilised. Nonetheless, this survey suggests that incidental sex work occurs more often than researchers or policymakers have considered - if thought about at all—and the narratives of the interview participants further contributes to the destabilisation of categories including "incidental" and "professional," "sex" and "work."

Of the 215 people who responded affirmatively to my exploratory message, 44 consented to participate in an indepth interview about their experiences of incidental sex work; a further four were recruited through a call for participants posted on social media platforms (Facebook and Twitter), and two were (re)recruited from an earlier research project with gay students (Morris, 2017). This brought the total number of participants to fifty. The recruitment criteria disqualified anyone who had advertised as selling sex or outside of the specified age range (18 to 28 years old). My focus on younger men allowed for direct comparisons with existing research literature on "post-identity" among sexual minority adolescents and young adults (Morris, 2017; SavinWilliams \& Diamond, 2000).

\section{Procedures}

The semi-structured qualitative interviews took place between May 2015 and April 2016 in quiet locations which were publicly accessible such as bars, cafés, park benches, local libraries, or university buildings, depending on the level of privacy requested by participants (see below). The interview schedule included 30 questions, divided into three sections: "Understanding Sexuality," "Experiences of Selling Sex," and "Thoughts and Feelings." As Connell and Hart (2003) have suggested, semi-structured interviews allow for participants to "discuss their experiences of sex work within a relatively open framework" (p. 
12). As such, the use of open-ended questions and prompts allowed for more free-flowing conversations to emerge during the interview encounters, which lasted between 45 and $75 \mathrm{~min}$. All participants were also asked to describe their profile photos, a form of photo-elicitation which promoted further discussion towards the end of the interviews. Researchers have identified the significance of visual media and methods for understanding gay, bisexual, and queer men's digital self-representations (see Bonner-Thompson, 2017; Morris, 2018; Mowlabocus, 2010; O’Neill, 2001; Walby, 2012). Given the study's focus on gay, bisexual, and queer men, and recognising that sexuality can be measured and understood differently across time and social context, all participants also competed a "sexuality form" which asked them to tick their current understanding of themselves, cross their future understanding of themselves, and circle their ideal understanding of themselves on a ninepoint scale (similar to the Kinsey scale), which contributed to discussions about sexual normativity, perceptions of continuity and change, and other topics relevant to this research project (see Vrangalova \& Savin-Williams, 2012; Savin-Williams, 2017). Other research projects using this method have understood the nine-point scale as "multiple overlapping categories," drawing on traditional psychological and sexological (positivist) methods of measurement (Savin-Williams et al., 2017, p. 2). However, in this study, the forms were used as a prompt for more open-ended conversations about sexual categorisation and labelling.

The interviews were audio-recorded using a smartphone, transcribed and coded by the author, then organised around themes which emerged throughout the data collection and analysis procedures (Goetz \& LeCompte, 1984). The analysis was further informed by research literature described above to identify common themes. Therefore, this paper adopts a modified grounded theory approach to data analysis which draws on both inductive thematic coding with insights from existing research in the field (Charmaz, 2014). Although saturation was achieved after approximately half of the interviews had been completed, in terms of original themes emerging, I continued with data collection to provide a more geographically distributed sample-showing that incidental sex work occurred consistently across major cities in all parts of England and Wales. Although qualitative research cannot be generalised beyond the sample, it is reasonable to assume that incidental sex work occurs in every city where geolocation apps and sites are available to arrange sexual encounters between men. This paper focuses on (1) "Labels for Incidental Sex Work"; (2) "Stigmatising and Stereotypical Discourses"; and (3) "Normativity and Respectability," with other themes described in more detail elsewhere (see Morris, 2018).

\section{Ethics}

This study was granted approval by an ethics committee of the author's institution and doctoral supervisors, and all guidelines set out by the British Sociological Association and Economic and Social Research Council were adhered to throughout the research process. Alongside the sexuality forms, all participants completed and signed a consent form after reading an information sheet, which assured them of their rights to withdraw participation, refuse to answer questions, and have their information stored anonymously and securely. Pseudonyms have been used here and elsewhere to protect the identities of all participants (Morris, 2018). Most participants were comfortable talking about their experiences in semi-public spaces, given that we could change the topic of conversation or discreetly pause the interview at any moment. Fully private settings were also offered and made available to all participants who required this. Nonetheless, despite taking these steps, the study raised significant ethical dilemmas including whether incidental sex work should be identified or studied at all, a question which I return to in the Discussion section.

\section{Participants}

Given the recruitment strategies described above, most participants lived in urban areas across England and Wales. Specifically, 5 were from South Wales, 5 were from South West England, 5 were from The Midlands, 7 were from South East England, 8 were from North East England and 10 were from Greater London. I focused on densely populated cities because these were locations in which social media platforms were more frequently used to facilitate sexual encounters (Morris, 2018). There was also a strategic rationale to choosing research sites where incidental sex work encounters were more likely to occur, given that greater online activity corresponded with more opportunities for spontaneous interactions. Despite this focus on urban areas, the geographical distribution of participants was broadly reflective of population density across England and Wales as it stood at the time of the 2011 census.

Concerning sexuality labels, at the time of the interviews, 19 participants identified as exclusively gay, 12 as gay, 11 as mostly gay, and 8 as bisexual. Concerning race labels, 2 identified as Asian, 5 as Black, 5 as Mixed, and 38 as White British. Concerning class labels, 4 identified as upper-middle-class, 20 as middle-class, and 26 as working-class. Complicating the former, two participants rejected the label of gay, preferring to identify as queer. 
Complicating the latter, several participants described their socio-economic positionalities as a changing characteristic in relation to career and educational opportunities such as going to university. Almost half of the participants were in full-time education, with 4 at sixth-form or foundation level, 6 at postgraduate level ( 2 doctoral students, 2 master's students, and 2 medical students), and 15 undergraduate level. Degree subjects included criminology, economics, geography, history, languages, law, international relations, marine operations, media production, musical theatre, philosophy, politics, psychology, and theology. As noted above, two participants were recruited from another research project with gay students (Morris, 2017). This compares with similar studies which found a high level of educational capital among sex working students (see Jenkins, 2009; Sanders et al., 2017; Walby, 2012). Student sex work is an expanding area of academic research and social policy intervention (see Roberts et al., 2013; Sagar et al., 2015).

Among the 26 participants who were not in full-time education, two were doctors, two were teachers, two were unemployed, two worked in the financial sector, two worked in the energy sector, two worked in retail, and five worked in bars or pubs. Other primary occupations or sources of income included actor, cabin crew, chef, clinical scientist, legal services, mental health care, personal assistant, recruitment coordinator, and security supervisor. It is important to note that some of these jobs were part-time, supplemented by additional sources of income, and some of those listed above also worked alongside their studies. As Bowen (2015) has noted, many people "supplement square work with sex work" (p. 434), and as I have noted elsewhere, low incomes and student debts were an "additional economic burden which influenced their decision to sell sex" (Morris, 2018, p. 185). Nonetheless, given the diverse occupational and socio-economic backgrounds of the participants, this study further contributes to research demonstrating that sex work has become an increasingly middle-class economic activity, even among those who do not consider it a "job" in the traditional sense (see Bernstein, 2007; Bimbi, 2007; Sanders et al., 2017; Walby, 2012).

\section{Results: Labels for Incidental Sex Work}

The term "sex work" has been identified as a more inclusive way to signify a diverse set of economic, social, and sexual practices (Jones, 2020; Leigh, 1997; Morris, 2018). Therefore, this study used the term "incidental sex work" to characterise the 358 paid sexual encounters described by the 50 participants. However, my use of this term could also be viewed as imposing a label, something which was called into question by several participants. For example, although he felt that "incidental sex worker is a term you could use," Alex added:

But, as I don't see this as a regular part of my life, I don't see any need to give it a name... If you did people's hair every now and again, you wouldn't call yourself an incidental hairdresser. It's just a thing that you do.

Similarly, contrasting incidental sex work with more "professional" forms of labour, Connor said:

I don't do it seriously enough to see it as a label. It's not my day job. I work in a restaurant, I'm a waiter, so that's something I get paid to do regularly. But I haven't done it enough times, and I don't see myself as a sex worker or an escort.

Connecting the irregularity of incidental sex work with it being a causal and nonprofessional practice, Sam said, "I'm not making it a regular thing, it just happens, it's more of an off-the-cuff kind of thing," and Jason said, "I wouldn't really define it as anything, because it's not something I do on a regular basis, it just happened." The notion that these young men's experiences of selling sex were events which "just happened" framed incidental sex work as something unremarkable or mundane, comparable with their experiences of unpaid sex, rather than an intentional form of work. As Tom said, "I did it once and I'm not doing it now. It wasn't really sex work. I mean, I guess it was, in that I got paid, but I wouldn't identify with those labels," and as Alfie said, "It isn't really a profession, it was just a one-off encounter". To elaborate on this distinction between "sex" and "work," it is worth considering how the participants defined their encounters more closely.

Given the casual, occasional, and nonprofessional nature of incidental sex work, almost all participants said "no" when asked whether they identified with labels such as "escort," "prostitute," "rent boy," and "sex worker." These responses were often framed around the economic significance of selling sex, where participants noted that it was not a primary source of income. For example, Rick said, "I can't imagine in what context I would adopt that identity, sex worker. It's not really relevant, because what I was doing was... not the same as people who consider it their only, or main source of income," Blake said, "To me, a sex worker is someone whose sole job and their only source of income, is having sex with people," and Adam said, "No, because I don't do it on a regular basis, I don't class it as a source of income." Among the 3 participants who did identify with labels such as sex worker, there was still some level of distancing themselves from the idea of this being a "professional" activity. For example, Robin said, "The thing is, for me, it's been a part-time thing, I've had another job, it's not something I've actively pursued. I do feel a level 
of solidarity with them, you know, but compared to someone where that is their only job, I've only done it a little bit," while Hari said, "I think you have to earn a label like that... I only did it twice... it would almost be wrong to say that I was one of them." These responses indicated a level of solidarity with "pro" sex workers, alongside explaining why many participants did not identify with conventional sex worker labels.

The most common reason participants gave for distancing themselves from sex work labels was that their behaviour was not "regular enough" to constitute an identity. Importantly, 19 participants agreed to sell sex just once, and only 7 participants sold sex more than ten times, which informed discussions around how-or indeed if - incidental sex work should be defined, labelled, and understood as an identity. For example, Dan said, "If you only do it once, to try it out, I don't think that really defines you," Rhys said, "I don't consider it prostitution if it's a one-time thing," and Amir said, "I wouldn't identify with any of those labels, no. Probably because it wasn't a regular thing, it was just something that kind of happened." Similarly, Matt said, "I wouldn't identify with any labels, because it was an in isolated incident or two", and Adrian said, "I wouldn't identify... because it was a one-time thing". The words "once-off" and "one-time thing" were repeated by 15 of the participants, while the words "regularity" and "regular thing" were repeated by 17 of the participants, to characterise their incidental sex work encounters.

Another way in which the participants distanced themselves from conventional sex work labels was potentially a feature of the recruitment criteria for this study (see above). Eleven participants said that their behaviours should not be understood using such labels because they did not "advertise" or "solicit." For example, Niall said, "I never put myself out there, I never advertised as a sex worker," while Gary said, "I feel that an escort advertises themselves, as someone who wants money for sex, whereas... I don't advertise myself for sex." Given that solicitation is illegal in England and Wales, these responses may reflect how current law informs the definition of "deviant" sexual identity labels. As noted in the previous section, the interviews included photoelicitation procedures, which prompted further discussion of how the participants represented themselves on social media platforms. For example, Josh said:

I don't identify with the word prostitute because, to me, that is something different. Prostitution is solicitation and I never solicit. I don't have adverts, I don't actively message people... I've never advertised what I do. I've never written it on my Grindr profile, or had the cues that are there.

Also referring to the subtle "cues" which can be used to advertise sex work on digital platforms which prohibit this being done explicitly (e.g. the diamond emoji on Grindr), Trevor said, "I've never tried to advertise it, I've never put a pound sign in my profile or whatever," and Ash said, "I don't think it's allowed on the site, so sometimes people put pound signs... Say your sentence was, "I'm looking to meet tomorrow afternoon," you'd put one pound sign in "aftfrnoon," and you'd have to infer it from that."

When asked how their paid sexual encounters could be described or labelled, participants provided a range of innovate responses. Examples included "An experimental experience" (Richard), "Payment for pleasure" (Josh), and "I'm a substitute prostitute" (Alex). Also describing his encounter as an "experiment," Tim said, "I feel that those labels would be more appropriate—certainly, say, sex worker-if you're earning a regular income from it. Rent boy and escort, similarly, you are doing it for the money." Using the descriptive terminology of medicine, to avoid identity labels, he added:

In medicine, for homosexuality, we say "men who have sex with men," which is pretty much the broadest brush you can throw, so "men who have sex with money?" Yeah, I think that's as broad as you can get. It's not a particularly snappy title. I'm not sure. It doesn't really roll off the tongue.

As someone with an educational background in science, now working for the National Health Service, it is worth noting that Tim began the interview by saying, "You just got me out of work, so my answers are going to be very clinical and direct, so I apologise for that." As Foucault (1978) observed, "the homosexual" emerged as a fixed identity category through medical discourses and modern institutions such as clinics.

Although the interview schedule did not include any questions about sexual health, clinical settings were another area in which the topic of labelling was raised. For example, discussing the term "sex worker," Josh said, "I always think of a clinic, because whenever I've gone and got checked, it always says 'sex workers' need to be kept safe." Relatedly, Mo said, "I knew that I was being really safe, but you never know. It's obviously a high-risk thing, that's why they ask at sex clinics," and Ash said that the only other people he had told about his encounter were "the clinic people" because, "They asked the question, they filled out some forms, and I feel like because it's confidential, and maybe it's important for your health, I'm not going to compromise my health just so that they don't think I'm disgusting." As I have noted elsewhere, "secrecy driven by sexual stigma can be a barrier to accessing healthcare" (Morris, 2018, p. 200). That several participants spontaneously associated the label of "sex worker" with clinics, health, and safety illustrates the continued associations between sex work and medical discourses, which has often been used to other, marginalise, and stigmatise. However, these narratives also highlight 
potential problems with healthcare policies which focus on labelling sexual minorities narrowly as "risky" subjects (see Ashford et al., 2020). Most of the participants had not disclosed their incidental sex work to anyone else, often for fear of normative judgement and sexual stigma. In the following sections, I turn to these topics as they were described by the participants in relation to sexual identities and respectability politics more broadly.

\section{Stigmatising and Stereotypical Discourses}

In addition to not viewing their behaviours as "professional" or "regular" enough to be labelled, several participants described how sex work stigma was related to their reluctance to identify with terms such as "prostitute," "rent boy," or "whore." For example, Brandon said, "Rent boy is the worst one, to be honest. I don't like the idea of it... being for rent, I take issue with that. As I said before, I have an issue with people taking ownership of other people." Similarly, Peter said, "Rent boy definitely has a lot of connotations... Incidentally being paid for sex, I don't come from the same category." Providing a list of the terms he did not like, Henry said, "I'm not a prostitute, or a whore, or a rent boy, they all just sound so low." Of note, several participants rejected these terms because they were seen as "lower class" (see Sanders, 2013). For example, Josh said, "If you label yourself as a prostitute, I feel like it's a lower class or a lower standard." He added, "Payment for pleasure makes it sound a lot more elegant and classy." By comparison, participants held more favourable attitudes towards the terms "escort" and "sex worker," even though they did not identify with them, for the reasons outlined above.

This avoidance of certain labels was also associated with "escorts" being perceived as having a greater level of agency (Weitzer, 2017). For example, Jacob said, "A rent boy is literally a male whore. You pay them for sex, that's it. Whereas, I always think of an escort as the type of person who you would willingly bring to a big business dinner, have them sit with you." These beliefs were often rooted in wider stereotypes about sex work. For example, Freddy said:

You think of people working on the street corner, the red-light district. You think of webcam shows, rent boy websites, stuff like that. You don't think of a 19-yearold boy on Grindr meeting two random people for $£ 20$ and $£ 50$. That wouldn't be the first port of call, if you ever said, "Think of a sex worker."

Relatedly, while recognising that, "This may sound really stereotypical," Josh said:

If it's a male prostitute, I never think of them being the top. I always think of them as the bottom, because they're being paid, they're going to do what they're told to do... I don't know why, but with prostitution,

I just think of a dead body lying there getting fucked.

Logan's (2017) research about online male escorting noted that "top" and "bottom" can be gendered and racialised labels, associated with higher and lower premiums respectively, although Walby (2012) has been sceptical of this conclusion drawn from a quantitative study, noting that exceptions exist such as "power bottoms." Alongside participants expressing concerns that selling sex would influence how others thought of them, several also suggested that stigma had led them to think about themselves in a negative way. This was sometimes expressed as a form of internalised stigma regarding their own experiences of sex work. For example, Nate said, "Even though it's called 'the oldest profession,' there's a massive stigma attached to it, in society. So, I think knowing that people would judge... makes you judge yourself." He added:

When it comes to judging it, I think people either tend to err on the side of sympathy to the point of condescension, where it's like, 'You must have had daddy issues, your parents can't have loved you'... or the other way they'll go is to just see you as the scum of the earth, basically."

On a similar note, Marcus said, "I think when you're younger, you look at it with the law, the way it is, and you look at it as wrong," and Peter said, "I grew up in a family with a fairly negative view of prostitution, and there is a general societal bias against it, which I had inadvertently subscribed to." These narratives support wider research literature on the negative effects of stigmatising discourses of sex work on social attitudes more broadly (O'Neill, 2001; Sanders, 2013), including among those who perform incidental sex work.

Other participants associated selling sex with stigma directed at promiscuity (see below). For example, Amir said, "I was a bit of a skank, but I don't think I was like a rent boy," and Dean said, "That puts people off you, it makes them think less of you, or think you're some kind of slag." He added, "I wouldn't chat about people I've had sex with, like 50-year-old men... It might affect the way certain friends think of me. I definitely wouldn't tell them I'd been paid." Derogatory views towards (some forms of) sex work led to some participants framing their experiences of selling sex in negative terms revolving around terms such as "slutty," "seedy" and "dirty." For example, Ethan said, "There's a very stigmatised view on selling sex, and sex workers, and prostitution, and escort work. Just because it's predominantly viewed as undesirable, dirty, people often associate prostitutes and escorts with drug users, and generally undesirable lifestyles." Similarly, Scott said, "It just 
didn't feel right. It made me feel a bit disposable, a bit used, and cheap, I suppose." Asked why he felt this way, he added, "I don't want to be constantly judging myself, essentially for something that lasted less than half-an-hour, thinking for days on end about why I did it, beating myself up." This demonstrates the significance of Rubin's (1984) charmed circle and the outer limits for drawing attention to the intersections between forms of sexual oppression.

For many participants, the sex work stigma they had experienced or internalised was related to wider forms of sexual normativity, such as slut-shaming and heterosexism. For example, describing his boyfriend's attitudes, Tim said:

He didn't really approve of it, I could see the sort of "risk factors" flashing up in his head and everything.

He made me get rid of the bag, you know, the satchel I bought, he made me get rid of that... I suspect because every time he looked at it, he would be reminded where it came from.

Asked why he had not told other people about his incidental sex work encounter, Tim added, "There is a social stigma attached to it. In the same way, I don't really advertise to my wider social network that I'm in an open relationship." These narratives can be useful for drawing attention to the ways in which sexual stigmas overlap in the maintenance of (hetero) normative ideals (Rubin, 1984; Tyler, 2014; Vance, 2011).

Other participants linked the theme of criminalisation to stigma and stereotypes. For example, Will said, "There's less stigma now, with people who do sex work as cam models... Obviously, if you're a cam worker it's less oppressive than other stuff" (see Jones, 2020). Also demonstrating a level of frustration at the idea of criminalising sex work, George said, "Yeah, fuck the politicians. If you don't want to do it, just don't pay someone." These narratives suggested concerns regarding the ability of the state, through law, to impose limitations on people's bodily autonomy. Many participants also appeared to be unconcerned about the law as they felt that it was unenforceable (see Walby, 2012) and fell into a similar category as other illegal activities such as the consumption of cannabis or the use of online streaming services. For example, Tim said, "When I torrent a film, I am breaking several copyright laws. I'm aware of it, I know it's bad, but the way I see it, much like copyright law, it's a bit of a silly law," Ethan said, "It's a bit like smoking weed. How are the police going to know what you do in private, anyway?" and Nate said, "Everyone does stuff at that age... I would smoke the odd spliff, and I was hooking up under 16." For these participants, private sexual encounters arranged online were viewed as impossible to regulate, so they had little or no concern about potential legal repercussions of their behaviours. For example, both Andy and Ben characterised such laws as "pointless" (see Walby, 2012).

\section{Normativity and Respectability}

As described in the Methods section, all of the participants completed a "sexuality form," which shaped our conversations about sexual attitudes, experiences, identities, and orientations. In this section, I draw comparisons between sexual normativity and respectability as it related to "sex work" identities, on the one hand, and "gay, bisexual, and queer" identities, on the other (see Augustín, 2007; Chateuvert, 2014; Grant, 2014). Among the participants who considered themselves "exclusively gay" at the time of the interviews, most felt that their sexual identities would be stable across time. However, many also expressed complex views about the social construction of sexuality. For example, Ryan said:

You can choose your sexuality, in a sense. So, that's about how you choose to share your body with, and it's a lot more complex than: straight, gay, or bi...

People's sexuality can change due to geography, and age, and experimenting, too.

Providing an example, he added, "Because you get straight men who have sex with men. They make a choice to have sex with a man, but they're not considered by society to be gay." This draws attention to another potential gap in sex work research, around so-called "gay-for-pay" forms of incidental sex work (see Escoffier, 2003). Focusing on his own sense of sexual fluidity, Greg said:

It fluctuates, I'd say. There are some days where I find myself much more attracted to girls, and I'll be thinking of girls, memories of being a teenager and having obsessions with girls all the time. But most of the time, I would say I'm more attracted to guys, recently. As I say, it changes. Sometimes you wake up in the morning and find yourself going on-if you're into social apps-going on Tinder rather than going on Grindr, just having the urge to meet a girl as opposed to a guy.

Similarly, Blake said, "I'm always open to that, because I like the idea of being more open and fluid," George said, "I see it as fluid. If one day I woke up and I wanted to have sex with a woman, I would be fine with that," and Jason said, "It doesn't really bother me, it's just who I'm attracted to at the time." When talking to another queer person, participants tended to express open attitudes towards sexual fluidity, as might be expected in a "postgay" social context (see Morris, 2017; Savin-Williams et al., 2017).

Although half of the participants did not think that their own sexuality would change, almost all recognised that sexual fluidity was a reality amongst their peers and 
in society more broadly (see Diamond, 2008; SavinWilliams, 2005). For example, Paul said, "Yeah, I think sexuality is probably a fluid thing. One of my housemates is lesbian, or she was lesbian, but now she's with a guy. Why box yourself into one, when you don't know what might happen?" Challenging narratives of "born this way" (Adler, 2018), Luke also said:

You're not stuck, you know. You're not born, and then you're going to be gay or bisexual. I'm not saying that I'm fluid, but obviously, you see some people who-I'm not going to say they "fit the box", because obviously that contradicts the whole point.

Other participants drew on the Kinsey scale-perhaps because the sexuality form was an extended version of this (see Savin-Williams, 2005)—to question the notion of fixed or rigid sexual categories. For example, Tim said, "I've flicked through the Wikipedia entry on Kinsey, so I know that sexuality is a scale, and most people are bisexual to some degree." He added, "In an ideal world, everyone would be bisexual, and aware of that, and comfortable... If someone gave me a little slidey-bar and said, "Where do you want to be on the scale?" I would quite happily move to bisexual." Among the 18 participants who identified as "mostly gay" and "bisexual leaning gay," there was even more fluidity to their self-perceptions, but also some experiences of bi-phobia and bi-erasure from within the LGBT community, especially other gay, bisexual, and queer men (see below).

Connecting with the pervious section, sexual normativity and respectability politics were themes which emerged during the interviews in a range of ways, especially among those participants whose "ideal" sexuality differed from their "current" understanding of themselves. Several participants described experiences of homophobia which was closely related to a perceived "failure" to meet heteronormative familial expectations. For example, Chris said, "My family are very conservative, so I found it very difficult to come out to them... My mum said, basically, 'If you are bisexual, choose to go with females', and offered to send me to a religious counsellor." He added, "It's not something that we discuss at home. I wouldn't introduce a guy, probably, unless I was in an a very long-term relationship." Relatedly, Simon said, "I'm not a self-hating gay, I just wish I had the straight lifestyle, because you have a man and wife, the kids, it's the norm. Whereas gays are slagging around until they're fifty and never really settle down," and Sam said, "I do like the idea of having a wife, girlfriend, that kind of thing... My parents have told me, 'You can't help who you love,' and it's true, but in an ideal world I would like to be heterosexual." When I asked why he could not have this, as a gay man, he added:
I guess, bad as it sounds, I want to fit in with the norm. I do like the way that I am, but there's always that niggling little thing in the back of your mind that says, you know, having a wife would be the perfect picture. Trying to fit in with society, and the norm.

As with the sex work stigma described in the previous section, some participants felt that they had "internalised" these attitudes from family members and the wider culture. Drawing on Duggan's (2002) definition of homonormativity, these narratives could also be interpreted as part of a "depoliticised gay culture anchored in domesticity and consumption" (p. 179), with an idealised vision of getting married and having children.

By comparison, the participants who defined themselves as "queer" strongly critiqued sexual conservatism and normativity, and associated this with the problem of rights-based strategies of assimilation. For example, Rick said, "I think the idea of getting rights from the state is fucked up, because the idea that the state has the power to give them in the first place is totally absurd, because they could just take them away." He added,

Straight people tolerate gay people, but they could just as easily push us away, withdraw the tolerance, and the people that leaves behind-people of colour, trans people, migrants-it's really fucked up... I don't believe in conformism in any sense.

Also sceptical of the white, cisgender, homonormative façade of identity politics, Hari said, "It's so veneery, do you know what I mean? It's the pretty half of the gay community. It's the nice, marriage equality, fathers with babies, that kind of shit." He added:

I also think the gay community, in public view, is desexualised. Gay people are like, 'Oh, hey queen, hey girl,' you know. Alan Carr, Graham Norton, gay men but without the sex. I don't have a problem with it, I love the camp, I just think sometimes the sex side of it is completely left out... You don't see gay people of colour that often, you don't see people like me.

Describing experiences of biphobia, Greg said that he has experienced "a lot of quite patronising, condescending comments. Particularly from gay people... There was a tendency to want to put me in a box, and because they couldn't do that with me, it frustrated them." Similarly, Jeremy said, "It actually makes telling people you're gay easier." These narratives, from the minority of participants who did not conform to the "gay norm," including gay, bisexual, and queer men of colour, illustrate the continued power of normalising judgement as a regulatory mechanism associated with labelling (see Logan, 2017; Weeks, 2017). 


\section{Discussion}

Drawing on an original empirical study about the attitudes and experiences of young men who performed incidental sex work, this study has raised conceptual, methodological, and political questions about the limitations of labelling sexual behaviours as identities. As noted in the Methods section, the study involved an adaptive and innovative approach to participant recruitment to reach an (until now) invisible group of young men who sold sex incidentally. Given the hidden nature of incidental sex work, there is an ethical dilemma implicit in publishing this research. For example, by defining a range of diverse sexual behaviours as "incidental sex work," I could be constructing a new identity label, one which most of the participants would reject. Conversely, by drawing attention to the previously unheard perspectives of young men who sell sex but do not identify as sex workers, this paper could further contribute to the queer intellectual and political projects of destabilising fixed identity categories, which may in turn contribute to decriminalising and destigmatising non-normative behaviours. Significantly, there were parallels between how participants deconstructed "gay" and "straight" labels through the notion of sexual "fluidity" (see Diamond, 2008; Savin-Williams et al., 2017), and how a "queer" perspective on sex work might be developed going forward. If more gay, bisexual, and queer men engage in casual, occasional, unplanned forms of sex work than do so "regularly" or "professionally"—as indicated by my survey of incidental sex work-then the dominant discursive constructions of sex work are also open to critique for being both othering and over-generalised.

I have chosen this special issue as the first place to publish research from this study because it has drawn together research with a focus on harm reduction strategies which move beyond debates about whether to decriminalise sex work, to consider how policy might be implemented. It is important to note that the young men in this study felt that such legal arguments were "irrelevant" to them. Similarly, Walby's (2012) research with online male escorts suggested that such encounters have "more to do with the diversity of sexualities among men who have sex with men than criminological or public health research agendas can account for" (p. 131). As I have explored in this paper, the limits of labels which have been constructed by advocacy, law, medicine, policy, and research simply do not apply to incidental sex work, as an ignored phenomenon. This erasure of subjects, alongside the innovative mixed methods drawn on during recruitment and interview procedures, mean that this study conformed to Halberstam's (1998) definition of "queer methodology." Furthermore, the "queerness" of incidental sex work-not merely in terms of the participants being gay, bisexual, and queer men-is that it is was an occasional (often "one time") behaviour which defied conventional practices of categorising, defining, naming, identifying, or labelling, as found in academia and activism alike (Foucault, 1978).

In the sex work research literature, dominant discourses of gender and sexuality are understood as limiting what can be imagined possible. To draw on Foucault's (2008) terminology, this grid of intelligibility tends to construct identities ("criminal," "deviant," "homosexual," etc.) through modern institutional and governmental logics. However, the narratives of the participants in this study do not conform to any dominant discourses of sex work, whether in terms of gendered violence, medical risk, or legal interventionism, on the one hand, or identity politics, labour rights, and sexual freedom, on the other. As the participants did not advertise or solicit, and arranged incidental sex work encounters online spontaneously, discourses about solicitation and public decency do not make sense; as the participants sold sex on an irregular basis or as a "one time thing," discourses about this being an organised form of labour do not make sense; as the participants were young men, discourses of gendered violence against women do not make sense. In short, this study demonstrates that the behaviours and experiences of people who sell sex are too diverse for any simplistic or singular narrative to be adequate or appropriate.

For the participants in this study, the law was not considered a relevant factor, demonstrating that criminalisation or regulation would have little to no effect on their irregular and nonprofessional behaviours. Nonetheless, criminalisation did contribute to sexual stigma, which also informed how the participants accessed sexual health services, described their experiences, and understood themselves as gay, bisexual, and queer young men who had sold sex within a hetero- or homo-normative, slut-shaming and whore-phobic culture. Demonstrating the continued relevance of Rubin's (1984) model of the "charmed circle" and "outer limits" of sexual respectability, this paper contributes to calls for decriminalisation as part of a wider process of destigmatising sexual diversity. This also supplements Rubin's (1984) call for an "anthropological understanding of different sexual cultures" without hierarchical (de)valuation or normative judgment (p. 284). Relatedly, drawing on research with male sex workers, Tyler (2014) argued that the "construction of casual sex and commercial sex as being the same type of experience except for the negotiation of a direct payment reinforces the complementarity of Rubin's charmed circle" (p. 145). This study further contributes to blurring the boundaries between casual/commercial, public/private, and good/bad sex on social media platforms (see Morris, 2018).

Importantly, although highlighting the limitations of identity politics, the deconstruction of "sex work" as a 
label does not necessarily undermine global campaigns for the decriminalisation of sex work (e.g. those advanced by Amnesty International, Bill and Melinda Gates Foundation, International Commission of Jurists, Joint United Nations Programme on HIV and AIDS, Office of the United Nations High Commissioner for Human Rights, Open Society Foundations, and the World Health Organisation, among others). These organisations have centred attention on health outcomes and human rights for all, rather than narrow moral and political claims about whether a person adopts the "correct" identity, or "right" set of behaviours, to be considered "worthy" of support within neoliberal regimes of responsibilitisation and welfarism (see Chapkis, 2017; O'Neill, 2001; Sanders, 2013). Given that this special issue was "based on the premise that it is possible to produce knowledge on community safety only with community involvement," on issues of criminal intervention and harm reduction, this paper calls on campaigners and organisers for sex work decriminalisation to consider sexual behaviours and identities—such as, but not limited to, incidental sex work-which have not yet been identified by policymakers or researchers, where the needs of hidden groups may be neglected.

Funding Economic and Social Research Council (ESRC).

\section{Declarations}

Conflict of Interest The author declares no competing interests.

Open Access This article is licensed under a Creative Commons Attribution 4.0 International License, which permits use, sharing, adaptation, distribution and reproduction in any medium or format, as long as you give appropriate credit to the original author(s) and the source, provide a link to the Creative Commons licence, and indicate if changes were made. The images or other third party material in this article are included in the article's Creative Commons licence, unless indicated otherwise in a credit line to the material. If material is not included in the article's Creative Commons licence and your intended use is not permitted by statutory regulation or exceeds the permitted use, you will need to obtain permission directly from the copyright holder. To view a copy of this licence, visit http://creativecommons.org/licenses/by/4.0/.

\section{References}

Adler, L. (2018). Gay priori: A queer critical legal studies approach to law reform. Duke University Press.

Agustín, L. (2007). Sex at the margins: Migration, labour markets and the rescue industry. Zed Books.

Ashford, C. (2009). Male sex work and the Internet effect: Time to re-evaluate the criminal law? The Journal of Criminal Law, 73(3), 258-280.

Ashford, C., Morris, M., \& Powell, A. (2020). Bareback sex in the age of preventative medication: Rethinking the 'harms' of HIV transmission. The Journal of Criminal Law, 84(6), 596-614.
Bernstein, E. (2007). Sex work for the middle classes. Sexualities, 10(4), 473-488.

Bimbi, D. S. (2007). Male prostitution: Pathology, paradigms and progress in research. Journal of Homosexuality, 53(1-2), 7-35.

Bonner-Thompson, C. (2017). 'The meat market': Production and regulation of masculinities on the Grindr grid in Newcastle-uponTyne, UK. Gender, Place \& Culture, 24(11), 1611-1625.

Bowen, R. (2015). Squaring Up: Experiences of transition from offstreet sex work to square work and duality-Concurrent involvement in both-in Vancouver, BC. Canadian Review of Sociology/ revue Canadienne De Sociologie, 52(4), 429-449.

Brown, W. (1997). The impossibility of women's studies. Differences: A Journal of Feminist Cultural Studies, 9(3), 79-102.

Campbell, R. (2014). Not getting away with it: Linking sex work and hate crime in Merseyside (pp. 55-70). The Policy Press.

Chapkis, W. (2017). Commentary: Response to Weitzer 'Resistance to sex work stigma.' Sexualities, 21(5-6), 743-746.

Charmaz, K. (2014). Constructing grounded theory. Sage.

Chateauvert, M. (2014). Sex workers unite: A history of the movement from Stonewall to Slutwalk. Beacon Press.

Connell, J., \& Hart, G. (2003). An overview of male sex work in Edinburgh and Glasgow: The male sex worker perspective. Occasional Paper, 8 .

Conner, C. T. (2019). The gay gayze: Expressions of inequality on Grindr. The Sociological Quarterly, 60(3), 397-419.

Diamond, L. M. (2008). Sexual fluidity. Harvard University Press.

Döring, N. M. (2009). The Internet's impact on sexuality: A critical review of 15 years of research. Computers in Human Behavior, 25(5), 1089-1101.

Duggan, L. (2002). The new homonormativity: The sexual politics of neoliberalism. In Russ Castronovo and Dana Nelson (Eds.) Materializing democracy: Toward a revitalized cultural politics, pp. 175-194.

Edelman, L. (2004). No future: Queer theory and the death drive. Duke University Press.

Epstein, S. (1994). A queer encounter: Sociology and the study of sexuality. Sociological Theory, 188-202.

Escoffier, J. (2003). Gay-for-pay: Straight men and the making of gay pornography. Qualitative Sociology, 26(4), 531-555.

Florêncio, J. (2021). Chemsex cultures: Subcultural reproduction and queer survival. Sexualities.

Foucault, M. (1977). Discipline and punish: The birth of the prison. A. Sheridan (Trans.). London: Penguin Books.

Foucault, M. (1978). The will to knowledge: The history of sexuality volume 1. R. Hurley (Trans.). London: Penguin Books.

Foucault, M. (2008). '21 March 1979.' In Davidson, A. and Burchell, G. (Eds.), The birth of biopolitics: Lectures at the Collège de France (pp. 1978-1979). Palgrave Macmillan.

Frost, N., Nolas, S. M., Brooks-Gordon, B., Esin, C., Holt, A., Mehdizadeh, L., \& Shinebourne, P. (2010). Pluralism in qualitative research: The impact of different researchers and qualitative approaches on the analysis of qualitative data. Qualitative Research, 10(4), 441-460.

Ghaziani, A. (2014). There goes the gayborhood? Princeton University Press.

Goetz, J., \& LeCompte, M. (1984). Ethnography and qualitative design in educational research. Academic Press.

Grant, M. G. (2014). Playing the whore: The work of sex work. Verso Books.

Gray, M. L. (2009). Out in the country: Youth, media, and queer visibility in rural America (Vol. 2). NYU Press.

Grov, C., \& Smith, M. D. (2014). 'Gay subcultures'. In V. Minichiello, \& J. Scott (Eds.), Male sex work and society. Harrington Park Press.

Halberstam, J. (1998). Female masculinity. Duke University Press.

Jenkins, S. (2009). Beyond gender: An examination of exploitation in sex work. (Doctoral dissertation, Keele University). 
Jones, A. (2015). Sex work in a digital era. Sociology Compass, 9(7), $558-570$

Jones, A. (2020). Camming: Money, power, and pleasure in the sex work industry. NYU Press.

Kaye, K. (2014). 'Male sex work in modern times'. In V. Minichiello, \& J. Scott (eds.) Male sex work and society. Harrington Park Press.

Lamble, S. (2013). Queer necropolitics and the expanding carceral state: Interrogating sexual investments in punishment. Law and Critique, 24(3), 229-253.

Leigh, C. (1997). 'Inventing sex work'. In J. Nagle (Ed.), Whores and Other Feminists. New York: Routledge.

Lister, K. (2020). A curious history of sex. Unbound Publishing.

Logan, T. D. (2017). Economics, sexuality, and male sex work. Cambridge University Press.

Masiero, C. M. (2017). Queering criminology. In P. Carlen \& L. França (Eds.). Alternative Criminologies. London: Routledge.

Minichiello, V., \& Scott, J. (Eds.). (2014). Male sex work and society. Harrington Park Press.

Morris, M. (2017). "Gay capital" in gay student friendship networks: An intersectional analysis of class, masculinity, and decreased homophobia. Journal of Social and Personal Relationships, 35(9), 1183-1204.

Morris, M. (2018). Incidental sex work: Casual and commercial encounters in queer digital spaces (Doctoral dissertation, Durham University).

Morris, M. (2019). Homophobia. In Bernat, F. and Frailing, K. (Eds.) The encyclopedia of women and crime, Wiley Online Library.

Mowlabocus, S. (2010). Gaydar culture: Gay men, technology and embodiment in the digital age. Ashgate Publishing.

Nuttbrock, L. (Ed.). (2018). Transgender sex work and society. Harrington Park Press.

O'Neill, M. (2001). Prostitution and feminism: Towards a politics of feeling. Polity Press.

Plummer, K. (1979). 'Misunderstanding labelling perspectives'. In Newburn, T. (Ed.) (2012) Key Readings in Criminology. London: Routledge.

Plummer, K. (1995). Telling sexual stories: Power, change and social worlds. Routledge.

Roberts, R., Jones, A., \& Sanders, T. (2013). Students and sex work in the UK: Providers and purchasers. Sex Education, 13(3), 349-363.

Rubin, G. (1984). 'Thinking sex: Notes for a radical theory of the politics of sexuality'. In Vance, C. (Ed.) Pleasure and danger: Exploring female sexuality. London: Pandora Press.

Sagar, T., \& Jones, D. (2017). "Not in our name": Findings from Wales supporting the decriminalisation of sex work'. In T. Sanders, \& M. Laing (Eds.) Policing the Sex Industry: Protection, Paternalism and Politics. London: Routledge.

Sagar, T., Jones, D., Symons, K., Bowring, J., \& Roberts, R. (2015). Student participation in the sex industry: Higher education responses and staff experiences and perceptions. Journal of Higher Education Policy and Management, 37(4), 400-412.

Sanders, T. (2013). Sex work. Routledge.

Sanders, T., Scoular, J., Campbell, R., Pitcher, J., \& Cunningham, S. (2017). Internet sex work: Beyond the gaze. Springer.

Savin-Williams, R. (2005). The new gay teenager. Harvard University Press.

Savin-Williams, R (2017). Mostly straights: Sexual fluidity among men. Harvard University Press.

Savin-Williams, R. C., \& Diamond, L. M. (2000). Sexual identity trajectories among sexual-minority youths: Gender comparisons. Archives of Sexual Behavior, 29(6), 607-627.

Savin-Williams, R. C., Cash, B. M., McCormack, M., \& Rieger, G. (2017). Gay, mostly gay, or bisexual leaning gay? An exploratory study distinguishing gay sexual orientations among young men. Archives of Sexual Behavior, 46(1), 265-72.

Shrage, L. (1994). Moral dilemmas of feminism: Prostitution, adultery, and abortion. Routledge.

Spade, D. (2015). Normal life: Administrative violence, critical trans politics, and the limits of law. Duke University Press.

Todd, Z., Nerlich, B., McKeown, S. and Clarke, D. (Eds.) (2004). Mixing Methods in Psychology. New York: Psychology Press.

Tyler, A. (2014). 'Advertising male sexual services'. In In V. Minichiello, $\&$ J. Scott (eds.) Male sex work and society. Harrington Park Press.

Vance, C. (2011). Thinking trafficking, thinking sex. GLQ: A Journal of Lesbian and Gay Studies, 17(1), 135-143.

Vrangalova, Z., \& Savin-Williams, R. C. (2012). Mostly heterosexual and mostly gay/lesbian: Evidence for new sexual orientation identities. Archives of Sexual Behavior, 41(1), 85-101.

Walby, K. (2010). Interviews as encounters: Issues of sexuality and reflexivity when men interview men about commercial same sex relations. Qualitative Research, 10(6), 639-657.

Walby, K. (2012). Touching encounters: Sex, work, and male-for-male internet escorting. University of Chicago Press.

Walkowitz, J. R. (1982). Prostitution and Victorian society: Women, class, and the state. Cambridge University Press.

Wardlaw, R. (1842). Lectures on female prostitution: Its nature, extent, effects, guilt, causes, and remedy. Glasgow: J. Maclehose.

Weeks, J. (2017). Sexuality (4th ed.). Routledge.

Weitzer, R. (2017). Resistance to sex work stigma. Sexualities, 21(5-6), 717-729.

Whittle, S. (2005). 'Gender Fucking or Fucking Gender?' In Morland, I. \& Willcox, A. (Eds.), Queer theory. Palgrave Macmillan.

Publisher's Note Springer Nature remains neutral with regard to jurisdictional claims in published maps and institutional affiliations. 